\title{
Potential signaling pathway involved in sphingosine-1-phosphate-induced epithelial-mesenchymal transition in cancer (Review)
}

\author{
YE ZENG $^{1}$, XING-HONG YAO ${ }^{2}$, ZHI-PING YAN ${ }^{1}$, JING-XIA LIU $^{1}$ and XIAO-HENG LIU ${ }^{1}$ \\ ${ }^{1}$ Institute of Biomedical Engineering, School of Preclinical and Forensic Medicine, Sichuan University, Chengdu, \\ Sichuan 610041; ${ }^{2}$ State Key Laboratory of Oncology in South China, Department of Radiation Oncology, \\ Sun Yat-Sen University Cancer Center, Guangzhou, Guangdong 510060, P.R. China
}

Received March 14, 2015; Accepted May 24, 2016

DOI: $10.3892 / \mathrm{ol} .2016 .4661$

\begin{abstract}
The developmental process of epithelial-mesenchymal transition (EMT) occurs when epithelial cells acquire invasive mesenchymal cell characteristics, and the activation of this process has been indicated to be involved in tumor progression. EMT could be induced by growth factors, cytokines and matrix metalloproteinases (MMPs). sphingosine-1-phosphate (S1P) is a biologically-active lipid that plays an important role in cancer metastasis. S1P also contributes to the activation of EMT. However, the mechanism underlying S1P-induced EMT is unclear. Increased evidence has demonstrated that the cell surface glycocalyx is closed associated with S1P and plays an important role in tumor progression, suggesting that S1P-induced EMT could be Snail-MMP signaling-dependent. Thus, we hypothesize that an S1P-glycocalyx-Snail-MMP signaling axis mediates S1P-induced EMT. This is an essential step towards improved understanding of the underlying mechanism involved in S1P-regulted EMT, and the development of novel diagnostic and anticancer therapeutic strategies.
\end{abstract}

\section{Contents}

1. Introduction

2. Hypothesis

3. Evaluation and rationale of the hypothesis

4. Conclusion

Correspondence to: Professor Ye Zeng, Institute of Biomedical Engineering, School of Preclinical and Forensic Medicine, Sichuan University, 3-17 Renmin South Road, Chengdu, Sichuan 610041, P.R. China

E-mail: yeqgzeng@gmail.com

Key words: sphingosine-1-phosphate, epithelial-mesenchymal transition, matrix metalloproteinase, glycoclayx

\section{Introduction}

The developmental process of epithelial-mesenchymal transition (EMT) occurs when epithelial cells acquire invasive mesenchymal cell characteristics, and the activation of this process has been indicated to be involved in tumor progression (1-3). EMT is associated with decreased expression of epithelial-specific genes, such as E-cadherin, and an increase in the expression of mesenchymal-specific genes, including $\mathrm{N}$-cadherin and vimentin $(4,5)$. EMT is believed to ultimately promote tumor metastasis by promoting the migration of tumor cells across the basement membrane and their invasion into the surrounding microenvironment $(2,6)$. Understanding the mechanism underlying EMT has profound results with regard to the responsiveness of a tumor to a range of available treatments.

Numerous studies have demonstrated that the interaction of tumor cells with their microenvironment can induce the expression of growth factors, cytokines and matrix metalloproteinases (MMPs), further leading to EMT (7-9). The transforming growth factor- $\beta$ (TGF- $\beta$ ), Wnt, Notch and nuclear factor- $\kappa \mathrm{B}(\mathrm{NF}-\kappa \mathrm{B})$ signaling pathways have been found to be critical for EMT induction (10,11). Sphingosine-1-phosphate (S1P), a biologically-active lipid, has been found to play a vital role in inflammatory diseases and cancer. It has been shown that S1P contributes to tumor metastasis by modifying the extracellular environment and via the induction of the invasion, motility and migration of cells to other locations, as well as by EMT $(12,13)$.

The tumor extracellular environment provides various stimuli (such as interstitial fluid shear stress and traction force) and the matrix for adjacent cells to contact. An early and decisive event during tumor development is hypoxia, which triggers a metabolic shift and induces processes such as coagulation, angiogenesis and extracellular matrix (ECM) remodeling $(14,15)$. The glycocalyx localizes at the surface of stromal and malignant tumor cells, and regulates a diverse range of molecular activities involved in cell-cell and cell-matrix interactions, as well as ECM remodeling. Recently, the glycosaminoglycans (GAGs) of the glycocalyx were indicated to play important roles in the mechanotransduction pathways involved in flow-regulated tumor invasion and metastasis (16). In the 
present review, we postulate that the glycocalyx takes center stage in S1P-induced EMT.

\section{Hypothesis}

We hypothesize that S1P promotes EMT in cancer by remodelling the glycocalyx and inhibiting the Snail-MMP signaling pathway. S1P plays a vital role in EMT, and the identification of an S1P-glycocalyx-Snail-MMP signaling axis could provide insight into novel anticancer therapeutic strategies.

\section{Evaluation and rationale of the hypothesis}

Cell surface glycocalyx is closely associated with tumor progression. The glycocalyx is a complex layer of numerous membrane-bound macromolecules that covers the mammalian cell surface (17). The glycocalyx is mainly formed from glycoproteins that bear acidic oligosaccharides and terminal sialic acids, as well as proteoglycans with their associated GAG side chains (17). Distinct disaccharide unit repeats characterize the GAGs and give rise to a variety of components, including chondroitin sulfate (CS), heparan sulfate (HS) and hyaluronic acid (HA). Sulfated GAGs covalently attach themselves to specific sites within proteoglycans (18). The syndecan family and glypican family are two major protein core families of HS proteoglycans that occur in almost all mammal cells. In syndecan-1, two extra sites positioned closer to the membrane are reserved for CS (18). HA is a disaccharide polymer of greater length (1,000-10,000 kDa), which is synthesized on the cell surface and interacts with $\mathrm{HA}$ receptors, such as the transmembrane glycoprotein CD44, and CS chains (19).

The changes in the structure and function of the glycocalyx are associated with disease occurrence. The components of the glycocalyx, including syndecans, glypicans and HA, serve as potential prognostic markers. Under specific pathophysiological conditions, including tumor onset, progression and metastasis, the expression and shedding of the glycocalyx components can be changed (20). As the most well-characterized syndecan family member, syndecan-1 is mainly expressed by epithelial cells (21). In breast carcinoma, the loss and overexpression of syndecan-1 correlates with a poor prognosis and an aggressive phenotype (22-24). In in vitro models of breast cancer, syndecan-1 is able to promote tumorigenesis via the regulation of tumor cell spreading and adhesion, proliferation and angiogenesis $(25,26)$. Syndecan-4 is widely expressed in the normal human mammary epithelium, albeit typically at low levels, and it is the second most prolific HS proteoglycan that is produced by the majority of breast carcinoma cell lines (27). Excess focal adhesion formation is promoted by the overexpression of syndecan-4, resulting in a reduced level of cell migration (28). Additionally, syndecan-4-deficient mice and cells exhibit impaired wound repair and mesenchymal cell migration $(29,30)$. Glypicans that are localized on the cell surface via a glycosylphosphatidylinositol moiety may regulate the cell responses to cell adhesion molecules and the ECM. Human breast and pancreatic cancer cells strongly express glypican-1 $(31,32)$, and it is required by pancreatic cancer cells for efficient TGF- $\beta$ signaling (33). HA is also

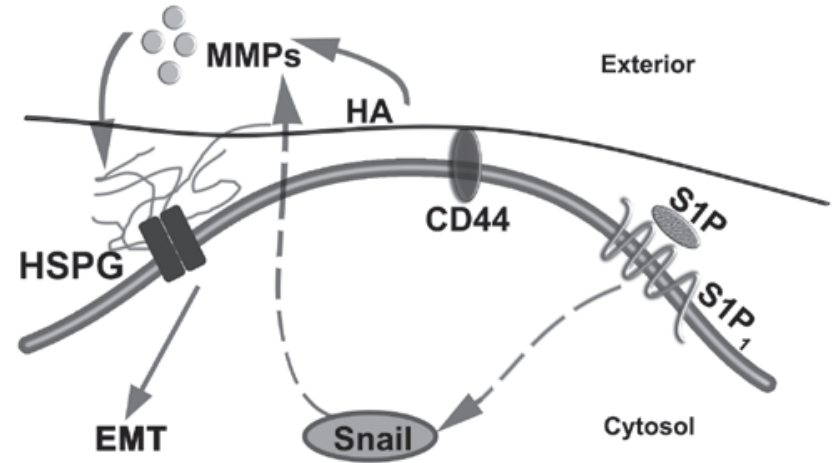

Figure 1. Glycocalyx-Snail-MMP signaling axis potentially involved in S1P-induced EMT in cancer. MMPs, matrix metalloproteinases; HSPG, heparan sulfate proteoglycans; HA, hyaluronic acid; $\mathrm{CD}$, cluster of differentiation; S1P, sphingosine-1-phosphate; EMT, epithelial-mesenchymal transition.

closely correlated with tumor cell growth, proliferation and metastasis. Recent studies have shown elevated serum HA levels in breast cancer patients (34).

Close association between the glycocalyx and S1P and MMPs. S1P maintains the integrity of the endothelial glycocalyx structure and inhibits MMP activity. Recent studies showed that the release of MMPs degrades the syndecan-1 ectodomain and its associated GAGs when S1P levels fall below a critical range of 100-300 $\mathrm{nM}$ and S1P1 is vacated (35), and that S1P induces the recovery of the glycocalyx via the phosphoinositide 3-kinase (PI3K) signaling pathway (36). In another study, HA increased the secretion of MMP-2 and MMP-9 in multidrug-resistant MCF-7 cells, and such an effect was blocked by the NF- $\kappa$ B inhibitor BMS-345541 (37). Furthermore, HA has been shown to activate the secretion of MMP-2 in time- and focal adhesion kinase-dependent manners in a QG90 cell line derived from human small cell lung carcinoma (38).

Tumor invasion and metastasis is inhibited after shedding of the glycocalyx. A study showed that the physiological levels of interstitial flow shear stress upregulated MMP levels and enhanced the motility of metastatic cells (16). The degradation of the glycocalyx on the tumor cell surface by hyaluronidase and heparinase blocked the flow-induced cell invasion. This study suggested that HA and HS play important roles in tumor invasion and metastasis.

SlP-induced EMT can be Snail-MMPs signaling pathway-dependent. S1P is formed by phosphorylation of sphingosine, catalyzed by sphingosine kinases 1 and 2 (39). S1P is a ligand for the S1P-specific G-protein coupled receptors, termed $\mathrm{S}_{1} \mathrm{P}_{1-5}$. The effects of S1P on cell invasion, motility and migration are mediated via receptor-dependent pathways (12,39-41). In general, $\mathrm{S}_{\mathrm{P}} \mathrm{P}_{1}$ is exclusively coupled with $\mathrm{G}_{\mathrm{i}}$ protein to activate cell migration through extracellular signal-regulated kinase, PI3K, Akt, phospholipase C and Rac signaling (42-44). The $\mathrm{S}_{\mathrm{P}} \mathrm{P}_{2}$ and $\mathrm{S}_{\mathrm{P}} \mathrm{P}_{3}$ receptors could couple with the $\mathrm{G}_{\mathrm{i}}, \mathrm{G}_{\mathrm{q}}$ and $\mathrm{G}_{12 / 13}$ proteins to inhibit cell migration via @ signaling $(41,45)$.

S1P modulates the levels of MMPs, such as MMP-2 and MMP-9, regulating cell invasion (46-48). Recent findings have suggested that EMT-associated MMPs are involved 
with the progression of cancer via three distinct mechanisms: i) Elevated MMPs levels in the tumor microenvironment are able to directly induce EMT in epithelial cells; ii) cancer cells that undergo EMT are able to generate more MMPs, facilitating cell invasion and metastasis; and iii) EMT is able to produce activated stromal-like cells that induce cancer progression through further production of MMPs (49). Previously, transcriptional profiling studies of Ras-transformed mouse mammary epithelial cells that were induced to undergo EMT by TGF- $\beta$ treatments demonstrated the upregulation of MMP-2, -12 and $-13(50,51)$. The TGF- $\beta$-induced EMT of MCF10A cells stimulated the expression of MMP-2 (52). Additionally, the expression of Snail in MCF-7 cells induced a MT1-MMP- and MT2-MMP-dependent invasion program (53). In SCp2 cells, Snail expression was MMP-3-dependent, as Snail levels decreased rapidly after MMP-3 withdrawal (54). The TGF- $\beta$ signaling pathway is the most extensively studied (55). TGF- $\beta$-induced EMT involves smad and non-smad pathway activation and is mediated by the transcriptional repressors and master regulators of EMT, such as Snail (56). Snail-knockdown inhibits cell migration and invasion induced by $\mathrm{NF}-\kappa \mathrm{B}$ and causes the suppression of inflammation-mediated breast cancer metastasis (10). Thus, Snail plays a vital role in TGF- $\beta$ and $N F-\kappa B$ signaling, as well as in MMP-induced EMT. Overall, it is possible that S1P-induced EMT is Snail-MMP signaling pathway-dependent.

\section{Conclusion}

EMT is a central process in tumor metastasis. S1P plays important roles in cell migration, motility and invasion. Numerous studies have shown the close association among S1P, the glycocalyx and the Snail-MMP signaling pathway, suggesting that a glycocalyx-Snail-MMP signaling axis mediates the S1P-regulated EMT in tumor progression and malignancy (Fig. 1). Once validated, the identification of this novel S1P-glycocalyx-Snail-MMP signaling axis may provide insight into novel diagnostic and anticancer therapeutic strategies.

\section{Acknowledgements}

This study was supported by the National Natural Science Foundation of China (grant no. 11402153) and the Talent Introduction Scientific Research Projects Funded Start-Up Funds of Sichuan University of China (grant no. 2082204174089).

\section{References}

1. Thiery JP and Sleeman JP: Complex networks orchestrate epithelial-mesenchymal transitions. Nat Rev Mol Cell Biol 7: 131-142, 2006.

2. Voulgari A and Pintzas A: Epithelial-mesenchymal transition in cancer metastasis: Mechanisms, markers and strategies to overcome drug resistance in the clinic. Biochim Biophys Acta 1796: 75-90, 2009.

3. Trimboli AJ, Fukino K, de Bruin A, Wei G, Shen L, Tanner SM, Creasap N, Rosol TJ, Robinson ML, Eng C, et al: Direct evidence for epithelial-mesenchymal transitions in breast cancer. Cancer Res 68: 937-945, 2008.

4. Takeichi M: Cadherin cell adhesion receptors as a morphogenetic regulator. Science 251: 1451-1455, 1991.

5. Thiery JP, Acloque H, Huang RY and Nieto MA: Epithelial-mesenchymal transitions in development and disease. Cell 139: 871-890, 2009.
6. Kalluri R and Weinberg RA: The basics of epithelial-mesenchymal transition. J Clin Invest 119: 1420-1428, 2009.

7. Orimo A, Gupta PB, Sgroi DC, Arenzana-Seisdedos F, Delaunay T, Naeem R, Carey VJ, Richardson AL and Weinberg RA: Stromal fibroblasts present in invasive human breast carcinomas promote tumor growth and angiogenesis through elevated SDF-1/ CXCL12 secretion. Cell 121: 335-348, 2005.

8. Barr S, Thomson S, Buck E, Russo S, Petti F, Sujka-Kwok I, Eyzaguirre A, Rosenfeld-Franklin M, Gibson NW, Miglarese M, et al: Bypassing cellular EGF receptor dependence through epithelial-to-mesenchymal-like transitions. Clin Exp Metastasis 25: 685-693, 2008.

9. Przybylo JA and Radisky DC: Matrix metalloproteinase-induced epithelial-mesenchymal transition: Tumor progression at Snail's pace. Int J Biochem Cell Biol 39: 1082-1088, 2007.

10. Huber MA, Azoitei N, Baumann B, Grünert S, Sommer A, Pehamberger H, Kraut N, Beug $\mathrm{H}$ and Wirth T: NF-kappaB is essential for epithelial-mesenchymal transition and metastasis in a model of breast cancer progression. J Clin Invest 114: 569-581, 2004.

11. Fuxe $\mathbf{J}$ and Karlsson MC: TGF- $\beta$-induced epithelial-mesenchymal transition: A link between cancer and inflammation. Semin Cancer Biol 22: 455-461, 2012.

12. Tabasinezhad M, Samadi N, Ghanbari P, Mohseni M, Saei AA, Sharifi S, Saeedi N and Pourhassan A: Sphingosin 1-phosphate contributes in tumor progression. J Cancer Res Ther 9: 556-563, 2013.

13. Milara J, Navarro R, Juan G, Peiró T, Serrano A, Ramón M, Morcillo E and Cortijo J: Sphingosine-1-phosphate is increased in patients with idiopathic pulmonary fibrosis and mediates epithelial to mesenchymal transition. Thorax 67: 147-156, 2012.

14. Belting M: Glycosaminoglycans in cancer treatment. Thromb Res 133 (Suppl 2): S95-S101, 2014

15. Pouysségur J, Dayan F and Mazure NM: Hypoxia signalling in cancer and approaches to enforce tumour regression. Nature 441: 437-443, 2006

16. Qazi H, Palomino R, Shi ZD, Munn LL and Tarbell JM: Cancer cell glycocalyx mediates mechanotransduction and flow-regulated invasion. Integr Biol (Camb) 5: 1334-1343, 2013.

17. Tarbell JM, Simon SI and Curry FR: Mechanosensing at the vascular interface. Annu Rev Biomed Eng 16: 505-532, 2014.

18. Jackson RL, Busch SJ and Cardin AD: Glycosaminoglycans: Molecular properties, protein interactions, and role in physiological processes. Physiol Rev 71: 481-539, 1991.

19. Henry CB and Duling BR: Permeation of the luminal capillary glycocalyx is determined by hyaluronan. Am J Physiol 277: H508-H514, 1999.

20. Choi S, Lee H, Choi JR and Oh ES: Shedding; towards a new paradigm of syndecan function in cancer. BMB Rep 43: 305-310, 2010.

21. Couchman JR: Syndecans: Proteoglycan regulators of cell-surface microdomains? Nat Rev Mol Cell Biol 4: 926-937, 2003.

22. Leivonen M, Lundin J, Nordling S, von Boguslawski K and Haglund C: Prognostic value of syndecan-1 expression in breast cancer. Oncology 67: 11-18, 2004.

23. Barbareschi M, Maisonneuve P, Aldovini D, Cangi MG, Pecciarini L, Angelo Mauri F, Veronese S, Caffo O, Lucenti A, Palma PD, et al: High syndecan-1 expression in breast carcinoma is related to an aggressive phenotype and to poorer prognosis. Cancer 98: 474-483, 2003.

24. Lendorf ME, Manon-Jensen T, Kronqvist P, Multhaupt HA and Couchman JR: Syndecan-1 and syndecan-4 are independent indicators in breast carcinoma. J Histochem Cytochem 59: 615-629, 2011.

25. Maeda T, Desouky J and Friedl A: Syndecan-1 expression by stromal fibroblasts promotes breast carcinoma growth in vivo and stimulates tumor angiogenesis. Oncogene 25: 1408-1412, 2006.

26. Beauvais DM and Rapraeger AC: Syndecans in tumor cell adhesion and signaling. Reprod Biol Endocrinol 2: 3, 2004.

27. Baba F, Swartz K, van Buren R, Eickhoff J, Zhang Y, Wolberg W and Friedl A: Syndecan-1 and syndecan-4 are overexpressed in an estrogen receptor-negative, highly proliferative breast carcinoma subtype. Breast Cancer Res Treat 98: 91-98, 2006.

28. Longley RL, Woods A, Fleetwood A, Cowling GJ, Gallagher JT and Couchman JR: Control of morphology, cytoskeleton and migration by syndecan-4. J Cell Sci 112: 3421-3431, 1999. 
29. Echtermeyer F, Streit M, Wilcox-Adelman S, Saoncella S, Denhez F, Detmar M and Goetinck P: Delayed wound repair and impaired angiogenesis in mice lacking syndecan-4. J Clin Invest 107: R9-R14, 2001.

30. Midwood KS, Valenick LV, Hsia HC and Schwarzbauer JE: Coregulation of fibronectin signaling and matrix contraction by tenascin-C and syndecan-4. Mol Biol Cell 15: 5670-5677, 2004.

31. Kleeff J, Ishiwata T, Kumbasar A, Friess H, Büchler MW, Lander AD and Korc M: The cell-surface heparan sulfate proteoglycan glypican-1 regulates growth factor action in pancreatic carcinoma cells and is overexpressed in human pancreatic cancer. J Clin Invest 102: 1662-1673, 1998.

32. Matsuda K, Maruyama H, Guo F, Kleeff J, Itakura J, Matsumoto Y, Lander AD and Korc M: Glypican-1 is overexpressed in human breast cancer and modulates the mitogenic effects of multiple heparin-binding growth factors in breast cancer cells. Cancer Res 61: 5562-5569, 2001.

33. Li J, Kleeff J, Kayed H, Felix K, Penzel R, Büchler MW, Korc M and Friess H: Glypican-1 antisense transfection modulates TGF-beta-dependent signaling in Colo-357 pancreatic cancer cells. Biochem Biophys Res Commun 320: 1148-1155, 2004.

34. Yahya RS, El-Bindary AA, El-Mezayen HA, Abdelmasseh HM and Eissa MA: Biochemical evaluation of hyaluronic acid in breast cancer. Clin Lab 60: 1115-1121, 2014.

35. Zeng Y, Adamson RH, Curry FR and Tarbell JM: Sphingosine-1-phosphate protects endothelial glycocalyx by inhibiting syndecan-1 shedding. Am J Physiol Heart Circ Physiol 306 : H363-H372, 2014

36. Zeng Y, Liu XH, Tarbell J and Fu BM: Sphingosine 1-phosphate induced synthesis of glycocalyx on endothelial cells. Exp Cell Res 339: 90-95, 2015.

37. Fang XJ, Jiang H, Zhu YQ, Zhang LY, Fan QH and Tian Y: Doxorubicin induces drug resistance and expression of the nove CD44st via NF-kB in human breast cancer MCF-7 cells. Oncol Rep 31: 2735-2742, 2014

38. Zhang Y, Thant AA, Hiraiwa Y, Naito Y, Sein TT, Sohara Y, Matsuda $S$ and Hamaguchi $\mathrm{M}$ : A role for focal adhesion kinase in hyluronan-dependent MMP-2 secretion in a human small-cell lung carcinoma cell line, QG90. Biochem Biophys Res Commun 290: 1123-1127, 2002.

39. Pyne NJ and Pyne S: Sphingosine 1-phosphate and cancer. Nat Rev Cancer 10: 489-503, 2010

40. Payne SG, Milstien S and Spiegel S: Sphingosine-1-phosphate: Dual messenger functions. FEBS Lett 531: 54-57, 2002

41. Huang YL, Huang WP and Lee H: Roles of sphingosine 1-phosphate on tumorigenesis. World J Biol Chem 2: 25-34, 2011.

42. Takabe K, Paugh SW, Milstien S and Spiegel S: 'Inside-out' signaling of sphingosine-1-phosphate: Therapeutic targets. Pharmacol Rev 60: 181-195, 2008.
43. Rosen H, Gonzalez-Cabrera PJ, Sanna MG and Brown S: Sphingosine 1-phosphate receptor signaling. Annu Rev Biochem 78 743-768, 2009.

44. Pchejetski D, Böhler T, Stebbing J and Waxman J: Therapeutic potential of targeting sphingosine kinase 1 in prostate cancer. Nat Rev Urol 8: 569-678, 2011.

45. Lepley D, Paik JH, Hla T and Ferrer F: The G protein-coupled receptor S1P2 regulates $\mathrm{Rho} / \mathrm{Rho}$ kinase pathway to inhibit tumor cell migration. Cancer Res 65: 3788-3795, 2005.

46. Kim ES, Kim JS, Kim SG, Hwang S, Lee CH and Moon A: Sphingosine 1-phosphate regulates matrix metalloproteinase-9 expression and breast cell invasion through S1P3-Gaq coupling. J Cell Sci 124: 2220-2230, 2011.

47. Moon A, Kim MS, Kim TG, Kim SH, Kim HE, Chen YQ and Kim HR: H-ras, but not N-ras, induces an invasive phenotype in human breast epithelial cells: A role for MMP-2 in the H-ras-induced invasive phenotype. Int J Cancer 85: 176-181, 2000.

48. Xin C, Ren S, Kleuser B, Shabahang S, Eberhardt W, Radeke H, Schäfer-Korting M, Pfeilschifter J and Huwiler A: Sphingosine 1-phosphate cross-activates the Smad signaling cascade and mimics transforming growth factor-beta-induced cell responses. J Biol Chem 279: 35255-35262, 2004.

49. Radisky ES and Radisky DC: Matrix metalloproteinase-induced epithelial-mesenchymal transition in breast cancer. J Mammary Gland Biol Neoplasia 15: 201-212, 2010.

50. Janda E, Lehmann K, Killisch I, Jechlinger M, Herzig M, Downward J, Beug H and Grünert S: Ras and TGF [beta] cooperatively regulate epithelial cell plasticity and metastasis: Dissection of Ras signaling pathways. J Cell Biol 156: 299-313, 2002.

51. Jechlinger $M$, Grunert $S$, Tamir IH, Janda E, Lüdemann $S$, Waerner T, Seither P, Weith A, Beug H and Kraut N: Expression profiling of epithelial plasticity in tumor progression. Oncogene 22: 7155-7169, 2003.

52. Kim ES, Sohn YW and Moon A: TGF-beta-induced transcriptional activation of MMP-2 is mediated by activating transcription factor (ATF) 2 in human breast epithelial cells. Cancer Lett 252: 147-156, 2007.

53. Ota I, Li XY, Hu Y and Weiss SJ: Induction of a MT1-MMP and MT2-MMP-dependent basement membrane transmigration program in cancer cells by Snail1. Proc Natl Acad Sci USA 106: 20318-20323, 2009.

54. Radisky DC, Levy DD, Littlepage LE, Liu H, Nelson CM, Fata JE, Leake D, Godden EL, Albertson DG, Nieto MA, et al: Raclb and reactive oxygen species mediate MMP-3-induced EMT and genomic instability. Nature 436: 123-127, 2005.

55. Moustakas A and Heldin P: TGF $\beta$ and matrix-regulated epithelial to mesenchymal transition. Biochim Biophys Acta 1840: 2621-2634, 2014

56. Xu J, Lamouille S and Derynck R: TGF-beta-induced epithelial to mesenchymal transition. Cell Res 19: 156-172, 2009. 